\title{
Experiences of peer counselling during inpatient rehabilitation of patients with spinal cord injuries
}

\author{
Karin Roth ${ }^{1} \cdot$ Gabi Mueller ${ }^{2} \cdot$ Adrian Wyss $^{3}$
}

Received: 11 May 2018 / Revised: 28 November 2018 / Accepted: 28 November 2018

(c) International Spinal Cord Society 2018

\begin{abstract}
Study design Qualitative study

Objectives The aim of this study was to evaluate peer counselling during inpatient rehabilitation of patients with spinal cord injuries (SCI). This article describes the experience with peer counselling from the perspective of patients with SCI as well as from the perspective of the peer counsellors.

Setting Inpatient rehabilitation of SCI in the Swiss Paraplegic Centre.

Methods Six interviews with patients and one focus group interview with professional peer counsellors have been evaluated using qualitative content analysis.

Results Patients experienced the peer counselling sessions as solution-oriented, practical, motivating and especially appreciated the authentic, open demeanor of the peer counsellors. Conversations about recreational activities, hobbies and interests supported the development of interpersonal relationships. Peer counsellors experienced the initial visits with patients with high level quadriplegia as a special challenge. The regular presence of all peer counsellors in the hospital facilitated an easier exchange with the patients.

Conclusion Patients feel empowered by peer counselling. Special attention should be placed on the timing of the initial visit. Unplanned meetings between patient and peers seem to be essential and highly valued. Peer counsellors are confronted with stressful situations in their work, therefore the need for support and training of peer counsellors should be further investigated.
\end{abstract}

\section{Introduction}

\section{Background}

Spinal Cord Injury (SCI) is an extremely dramatic event for any person, which affects the rest of their life. [1] The incidence of SCI in Switzerland is 18 per one million people yearly. [2] The objective of rehabilitation is to ensure that functioning is maximized and that an individual can be as independent as possible, in order to be able to actively

Karin Roth

karin.roth@paraplegie.ch

1 Department of Nursing Development and Education, Swiss Paraplegic Centre, Nottwil, Switzerland

2 Clinical Trial Unit, Swiss Paraplegic Centre, Nottwil, Switzerland

3 XUND, Colleges of professional education and training for Health professionals, Lucerne, Switzerland participate in life. [3] Physical and emotional strengthening, self-management and empowerment are central elements in the rehabilitation of SCI and are essential for its success. $[4,5]$ Self-management aims to promote knowledge and skills and to motivate patients to handle their condition or disability, and its consequences, in an active and competent manner. [6] Using peers to strengthen self-management skills has proven effective in other conditions and environments. [7-9] Empowerment of individuals with SCI is an important element of self-management which may also promote self-efficacy. [10]

Only a few studies have been conducted concerning the benefits of peer counsellors in inpatient rehabilitation of SCI. [11, 12] Peers have a supporting role in finding solutions to everyday practical problems, offer emotional support and can have a substantial impact on wellbeing and quality of life of individuals with recent SCI. [13] In individuals with SCI, this support results in building up selfconfidence as well as motivation and feelings of empowerment. [11] Veith et al. [11] and Haas et al. [13] mentioned 
in their studies that the initial meeting is of special importance, because it has an impact on the development of the relationship.

Veith et al. [11] addressed how the quantity of meetings with the peers influenced the quality of the relationship. While peer assignments are usually made based on the level of injury and the gender of the patient, timing of the initial visit, as well as planning and implementation of the visits can differ greatly. [11, 12, 14] Framework requirements and procedures for peer counselling in inpatient rehabilitation can differ and there are few insights about these procedures. Very little is known about the work experience of the peers and their personal needs.

\section{Objectives and issues}

The aim of this study was to evaluate how patients with SCI experienced peer counselling, especially the initial meeting, and how it affected their experience of empowerment. Secondly, the peers own perception of their counselling function was evaluated.

The following questions were addressed: what are the patients' experiences with peer counselling; which aspects of peer counselling support their ability to re-establish a self-determined life (empowerment) and what perceptions have the peer counsellors regarding their consulting work in terms of empowering the patients.

\section{Methods}

Peer counselling has been established for several years at the Swiss Paraplegic Centre, a specialized rehabilitation and acute care clinic. The peer counselling core team consists of four peers, who attend approximately $80 \%$ of the patients with a recent SCI. They serve approximately 150 patients per year. Other peers attend patients with other conditions than SCI or foreign language needs. All of them are employed by the hospital and are associated with the nursing teams. They frequently communicate with the nurses, occupational therapists and physiotherapists. There are other counselling services at the Swiss Paraplegic Centre such as vocational guidance, pastoral care and other services. Peer counsellors attend patients during therapy-free time periods, mainly in the evenings or sometimes in the afternoons. Patients are assigned to their peers primarily based on their level of injury and gender. The initial visit usually takes place after the first month of rehabilitation and further meetings are scheduled thereafter individually. Peers visit patients regularly in order to answer questions and to discuss relevant SCI-related topics. The peers are planning the visits themselves. The main purpose of peer counselling is the exchange of personal experience and addressing specific questions with someone who is in a similar situation.

\section{Sampling and recruitment}

A qualitative approach was selected for the study and reported according to the COREQ criteria. [15] Data were collected in semi-structured interviews over a period of 5 months. The patients were interviewed individually. The peers' perceptions were collected in a focus group interview. The data were collected by the first author (KR) who is an administrative member of the nursing team but not involved in bed side activities on the ward. There was no personal or professional interaction between the study team and the patients before the start of the study. We included German-speaking patients with SCI during their initial rehabilitation, aged from 18 to 75 years and the cognitive ability to respond to questions during a half-hour interview. Patients had to have participated in at least one meeting with a peer counsellor before the interview. Therefore the interviews were conducted approximately 2 months before the patient's discharge. During the interview, the number of meetings and the experience with peer counselling was explored.

Peers who have been actively counselling for more than 1 year were invited to take part in a focus group interview.

All persons who participated in this study were informed both orally (by KR) and in writing about the study and its aim and their written consent was obtained before participation. The study was approved by the local ethics committee.

A total of 20 consecutive patients from the discharge list were screened for study participation. A total of 14 patients were excluded (not German-speaking (5), not interested to participate (7) and other diagnosis than SCI (2)). Thus 6 patients were included in our study. A total of 4 peers met the inclusion criteria and all of them agreed to participate in the study. All interviews as well as the focus group were led by the first author (KR) with no other persons involved. The patient interviews took an average of $20 \mathrm{~min}$ each and the focus group interview lasted $75 \mathrm{~min}$. The demographic characteristics of the participants are presented in Table 1.

\section{Interviews}

The interviews were directed to investigate the research questions and were based on previous investigations. [13] The questions examined the following topics: experience of the initial visit, contents and procedures of any further meetings, relationship building and personal value gained (for more details see Table 2). Before the start of the study, the questions were run through a pre-test check to assess them for clarity. Additionally more in-depth questions were 
Table 1 Characteristics of the participants

\begin{tabular}{|c|c|c|c|c|c|c|}
\hline Code & $\begin{array}{l}\text { Age } \\
\text { [years] }\end{array}$ & $\begin{array}{l}\text { Gender } \\
{[\mathrm{m} / \mathrm{f}]}\end{array}$ & $\begin{array}{l}\text { Level of } \\
\text { Injury }\end{array}$ & $\begin{array}{l}\text { AIS Score } \\
{[\text { A-D }]}\end{array}$ & $\begin{array}{l}\text { Cause of } \\
\text { paralysis }\end{array}$ & $\begin{array}{l}\text { Duration of rehabilitation at the } \\
\text { time of interview [months] }\end{array}$ \\
\hline \multicolumn{7}{|c|}{ SCI patients } \\
\hline SCI1 & 25 & $\mathrm{~m}$ & C6 & $\mathrm{B}$ & trauma & 8 \\
\hline $\mathrm{SCI} 2$ & 28 & $\mathrm{~m}$ & T9 & $\mathrm{D}$ & illness & 6 \\
\hline $\mathrm{SCI} 3$ & 58 & $\mathrm{~m}$ & $\mathrm{C} 4$ & $\mathrm{D}$ & illness & 9 \\
\hline SCI4 & 48 & $\mathrm{f}$ & $\mathrm{C} 4$ & $\mathrm{D}$ & trauma & 5 \\
\hline SCI5 & 29 & $\mathrm{~m}$ & $\mathrm{C} 7$ & $\mathrm{~A}$ & trauma & 8 \\
\hline SCI6 & 73 & f & $\mathrm{C} 5$ & $\mathrm{C}$ & illness & 4 \\
\hline Code & $\begin{array}{l}\text { Age } \\
\text { [years] }\end{array}$ & $\begin{array}{l}\text { Gender } \\
{[\mathrm{m} / \mathrm{f}]}\end{array}$ & $\begin{array}{l}\text { Level of } \\
\text { Injury }\end{array}$ & $\begin{array}{l}\text { AIS Score } \\
{[A-D]}\end{array}$ & $\begin{array}{l}\text { Cause of } \\
\text { paralysis }\end{array}$ & $\begin{array}{l}\text { Duration for Injury for Peer } \\
\text { Counsellors is presented in } \\
\text { years }\end{array}$ \\
\hline \multicolumn{7}{|c|}{ Peer counsellors } \\
\hline $\mathrm{P} 1$ & 49 & $\mathrm{~m}$ & $\mathrm{~T} 4$ & A & trauma & 29 \\
\hline $\mathrm{P} 2$ & 45 & $\mathrm{f}$ & $\mathrm{T} 7$ & A & trauma & 10 \\
\hline P3 & 35 & $\mathrm{~m}$ & $\mathrm{C} 5$ & $\mathrm{C}$ & trauma & 15 \\
\hline $\mathrm{P} 4$ & 59 & $\mathrm{f}$ & $\mathrm{C} 6 / 7$ & A & trauma & 37 \\
\hline
\end{tabular}

SCI SCI patients, $P$ peer counsellor, $m$ male, $f$ female, $C$ cervical lesion, $T$ thoracic

lesion, AIS score American Spinal Injury Association Impairment Scale

Table 2 Key questions for the interview with patients and peer counsellors

Key questions

-Can you describe your experience at the initial visit?

-How did you experienced the timing of the initial visit?

-What was your impression coming away from the initial meeting?

-How did further meetings with the peer/the patient develop afterwards?

-Which topics came up in your conversations?

-What was particularly important for you in your exchange with the peer/the patient?

-Where there any particular experiences you made during the interview?

-What did you learn from the exchange?

-Were there commonalities between peer/patient?

-What else would you like to share?

presented when the conversation temporarily stopped, in order to get a better and more in-depth understanding of the statements. No interviews were repeated.

\section{Data analysis}

The individual interviews and the focus group interview were audio recorded without field notes, pseudonymized and then transcribed literally. The data analysis was carried out according to strict guidelines (Mayring's quality criteria).[16] This included the following steps: (a) Analyzing the transcripts line by line to extract meaningful content. (b) Paraphrasing the meaningful content in units in a concise and descriptive form. (c) Coding units and grouping those into subcategories. (d) The subcategories were then combined into categories and compared multiple times with the original data, to ensure that they reflect the core message of the interview. Finally anchor samples were collected to illustrate the character of the subcategories. No transcripts were returned to participants for comment and/or correction. The analysis was performed by the first author (KR). To improve credibility, the analysis was discussed with the last author (AW) until consensus was reached.

\section{Results}

\section{Perspective of patients with $\mathrm{SCl}$}

\section{First impression-lasting impression}

The memory of the initial meeting was characterized for several of the patients by the fact that for the first time, they had a conversation with another person in a wheelchair. Many of the patients were impressed by this first meeting and described it as a positive experience [see P1]. Several patients reported that this meeting left a lasting impression on them based on how an individual with SCI, confined to a wheelchair, can cope with life. One patient described her thoughts about the initial meeting as follows: "...I always thought: how can someone in a wheelchair prevail? Is life in a wheelchair worth living?... What a charisma she has. Just to meet someone (in a wheelchair) at all" [see P2]. The 
initial meeting was very helpful for many of them, just to be able to ask questions and to exchange thoughts with someone in a similar situation [see P3]. All of the patients could remember the initial meeting and its timeframe well. Patients considered the timing appropriate [see P4]. (Table 3a)

\section{To be able to talk about anything}

In principle, all the individuals concerned had the impression that they could discuss any topic with their peer [see P5]. The following topics were discussed quite frequently: bladder and bowel management, sexuality and relationships, as well as travel and leisure activities. Patients stated that they preferred not to discuss some topics with the medical staff, because the peer could give them much better input. Information exchanges about personal care and everyday experiences were especially relevant. "They (the medical staff) provided the assisting equipment, but they couldn't pass along the experience. I went straight to the peer..." [see P6].

\section{Finding solutions together}

Patients considered it particularly helpful to discuss different topics and also to apply and train practical solutions together. Different options were tried, until an optimal solution was found. It was helpful for the patients to develop their own solutions for everyday problems: "He showed me some tricks, but I later found a variation that simply worked better for me" [P7]. Patients really appreciated discussing everyday life topics. They also perceived this as different from the patient education they received from the professional staff [see P8].

\section{Beyond the wheelchair}

Finding similarities was considered important, especially with regard to the initial meeting [see P9]. The wheelchair was named as the most important similarity. Other important similarities were age and gender. Intimate topics were preferably discussed with a member of the same sex [see P10]. Age not only related to the age of the person but also to the number of years in a wheelchair [see P11].

However, for some patients, other similarities were more important [see P12]. The difference in the level of injury between patient and peer counsellor was not considered relevant by all patients. "That she's a para and I'm a quadriplegic makes no difference...because in the end we all have the same issues" [see P13].

\section{A positive attitude towards life is inspiring}

Patients reported that the peers were able to motivate them in a number of ways [see P14]. This supported trying out new things and acquiring a forward-looking attitude. Many of the patients found the peers' positive attitude towards life helpful and supportive. They were encouraged, because they saw how active and positive the peers were in spite of their limitations. The peer was therefore perceived as a great role model: "My peer has also travelled a lot...he's active in athletics and that's certainly a role model" [see P15].

\section{Trust was promoted through authenticity}

It was not only the positive and motivating attitude of the peers that was truly appreciated by the patients; in addition, the fact that the peers were willing to address difficulties and problems openly was important [see P16].The professional staff often passed on their instructions as they were outlined in the operating instructions. The counselling of the peers, on the other hand, focused more on real-life application. "I just think it's more realistic... and not as strict. They understand that there's still a life out there..." [see P17]. This open and honest approach was described as very authentic and helpful in establishing a trusting relationship.

\section{From the peer counsellors' view}

\section{To find the right moment}

For the peers, the timing of the initial meeting was a challenge. It was important for them to find the best possible time, and to approach the patients only when they were ready. The level of injury was the most important criteria for their initial visit. "It was always a balancing act. Do you go now or wait a little longer? If I go too early they may think: what does he want here? I can't even hold a cup in my hand. And here he is telling me that I'll be able to do this and that, all by myself" [seeC1]. The peers noted that the most important factors on the initial visit, in their opinion, were to gain some first impressions and to get to know each other [see C2]. (Table 3b)

\section{Meetings are not planned ahead}

The peers highlighted the fact that even unplanned meetings were used to exchange ideas and experiences during the rehabilitation. These meetings were considered important, because questions could be addressed when they arose. "All these short conversations, which we just happened to have: in front of the elevator, or in the basement. These can be quite brief like: hey, is it true that a decubitus can develop in as little as 20 min?" [see C3]. The peers told us that these brief exchanges were highly valued by the patients, and that they were at times able to benefit from them greatly, sometimes even more than from the planned meetings [see C4]. 


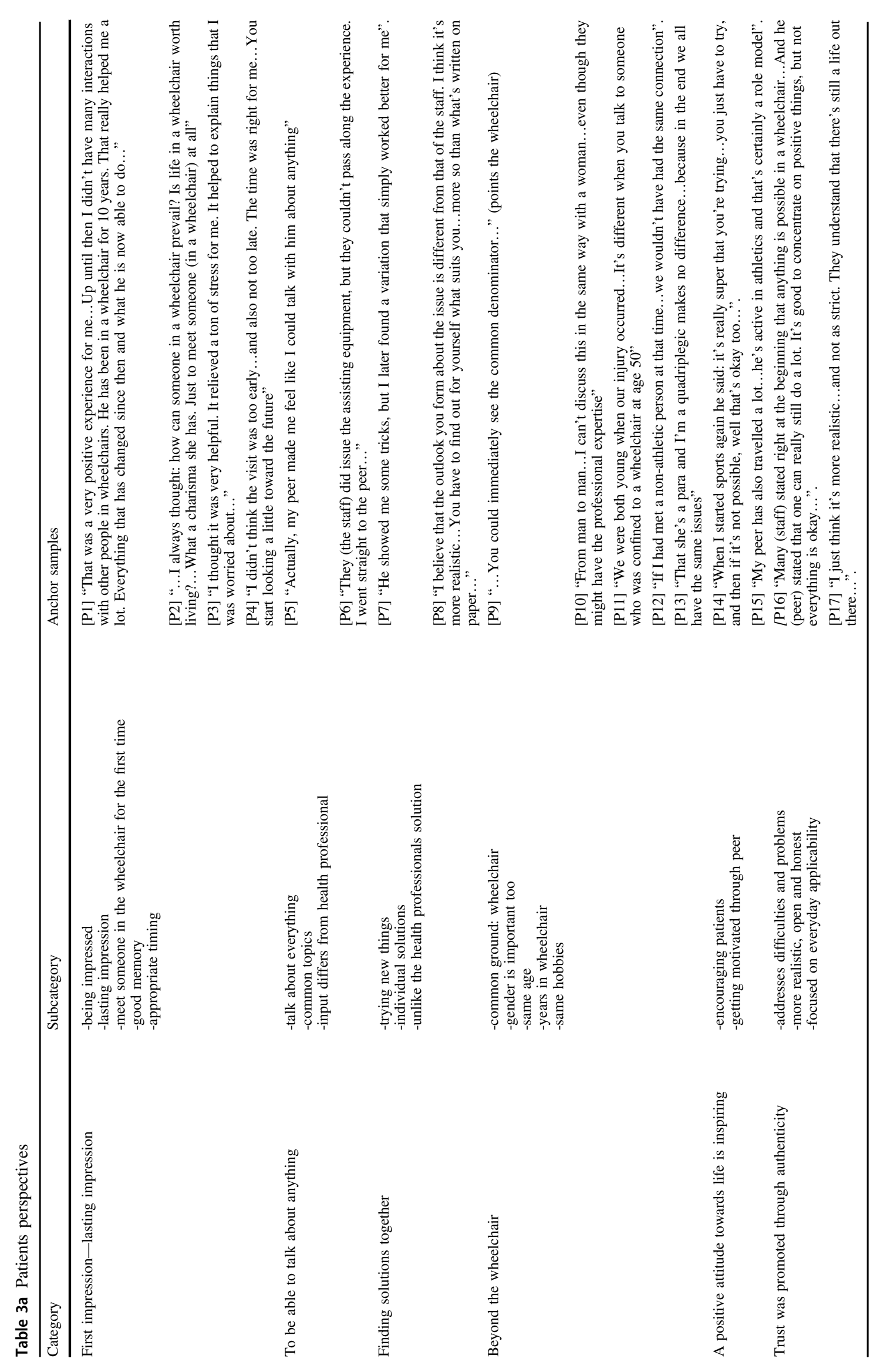




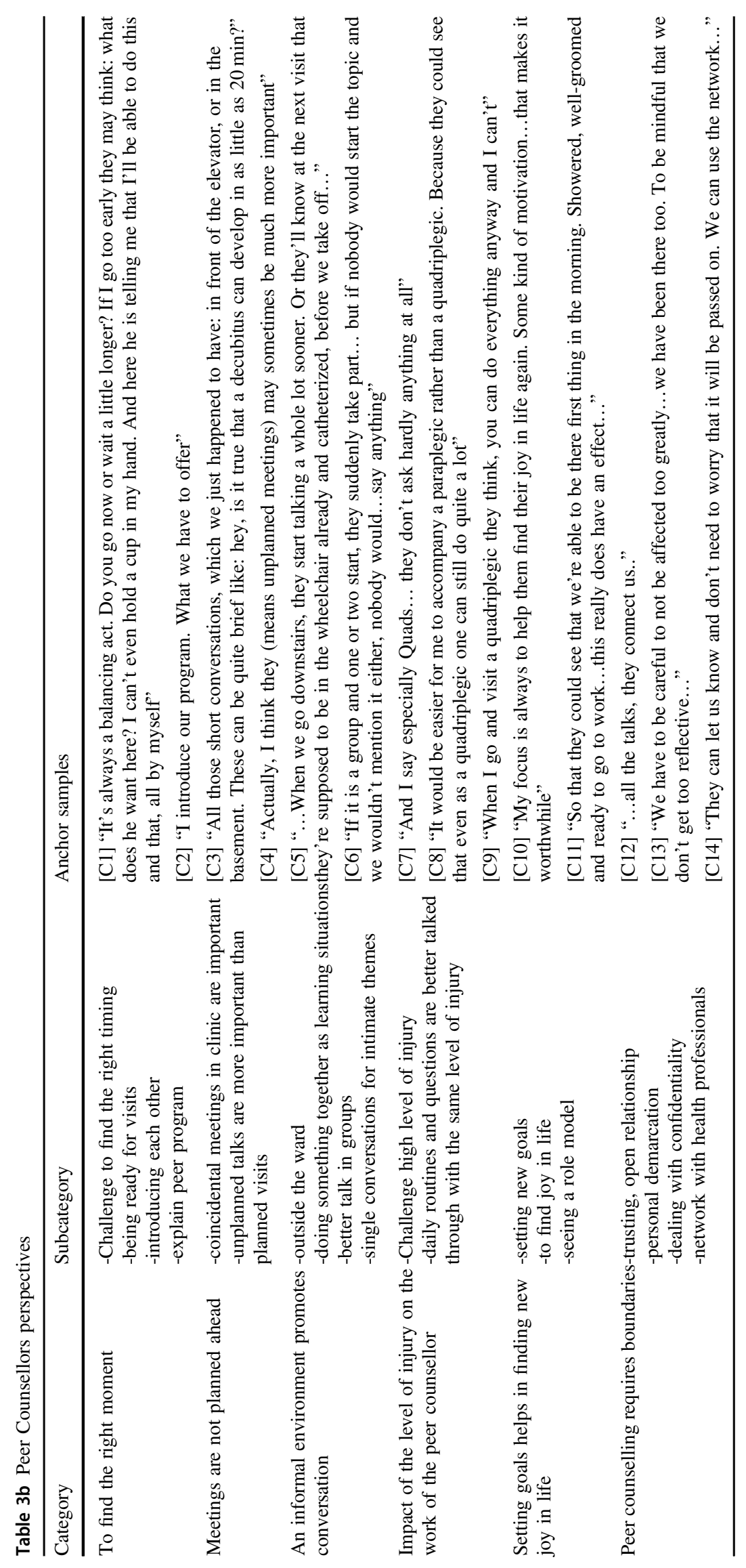




\section{An informal environment promotes conversation}

The peers usually chose a place other than the hospital ward for the meetings. They shared that the conversation was difficult at times, when they were just sitting across from each other. Being outside the patient's room and doing something together was helpful in initiating a conversation. In addition, these outings can be utilized as training situations. "...When we went out of the ward, they start talking a whole lot sooner. Or they will know at the next visit that they are supposed to be catheterized and in the wheelchair before we take off..." [see C5]. The peers emphasized that they often experienced patients to be more open in a group exchange, rather than in an individual conversation [see C6].

\section{Impact of the patient's level of injury on the work of the peer counsellor}

During the conversations, the peers repeatedly realized how important the level of injury was. In particular, patients with high-level quadriplegia needed more time to ask questions and to bring up topics [see C7]. Furthermore, the level of injury was particularly relevant when everyday practical issues were being discussed [see C8]. It was therefore considered to be especially challenging to counsel patients with high-level quadriplegia. "When I (peer counsellor) go and visit a quadriplegic patient, he thinks, you (paraplegic peer counsellor) can do everything anyway and I (quadriplegic patient) can't" [see C9].

\section{Setting goals helps in finding new joy in life}

Encouraging patients to set goals was very important for the peers. They focused on defining a goal together with the patient and working on it together. This helped the patient to become more forward-looking and to enjoy life again. "My focus is always to help them find their joy in life again. Some kind of motivation...that makes it all worthwhile" [see C10].

The peers were aware of their influence and knew that their own attitude towards life would make an impression on the patients [see C11].

\section{Peer counselling requires boundaries}

The peers had a very close relationship with the patients [see C12]. They emphasized how important it was for them to maintain some space between them and the patients. Some of the conversations brought up strong memories of their own trauma. "We have to be careful to not be affected too greatly... we've been there too. To be mindful that we don't get too reflective..." [see C13].
The fact that they are employed (including job descriptions) as peers at the rehabilitation clinic made it much easier. The confidentiality obligation facilitated discussions about very intimate topics and helped to build trusting relationships [see C14]. They found knowing the hospital personnel well was also very helpful.

\section{Discussion}

The objective of this study was twofold: first to understand how patients experienced peer counselling with regard to empowerment and secondly, to examine the records of peer counsellors during their work. The results showed that patients felt empowered and encouraged by peer counselling. The perspective of the peer counsellors showed a need for training and support in order to better cope with stressful situations.

Haas et al. [13] noted that the timing of the initial visit should be thoroughly considered. To date, there have been no recommendations regarding the best time for the initial visit with newly injured patients, in order not to overwhelm them. In this study, the initial visit has been described as a lasting, positive memory by all patients. It was especially important for those involved to see that life can go on in spite of the wheelchair. While the meeting was very emotional for the patients, the primary focus of the peer counsellors was more on structural and contextual aspects. The informational settings of the meetings with the patients and the possibility for 1:1 teaching of special tasks were mentioned specifically. For the peers, it was challenging to find the optimal time point for the initial visit, especially for patients with high-level quadriplegia. The acute phase of a person with a high-level quadriplegia is usually longer than that of a person with paraplegia, and thus persons with highlevel SCI may be overwhelmed at their initial visit. [17] The timing of the initial visit should therefore be considered based on the likely duration of rehabilitation and the level of injury.

Individuals with SCI found the exchange regarding leisure time activities, common hobbies and interests during their first contact with the peer counsellors very helpful. This exchange promoted communication in general and helped to build good relationships. Talking about personal, intimate topics and everyday practical skills was considered beneficial and useful. This observation is consistent with other studies [18] and also reflects the opinion of the peers.

The peers highlighted a very interesting and novel aspect. They explicitly described how valuable spontaneous conversations during unplanned meetings with the patients in the hospital were. The fact that the peers were employed by the clinic and were often in hospital, especially in the afternoons and evenings, made unscheduled contact with 
the patients possible. This facilitated uncomplicated discussions of current topics and other questions. Unplanned peer-patient exchanges were extremely helpful for patients and should therefore play a more important role in the rehabilitation process.

Although gender and level of injury are key factors in the assignment process, it was shown that these parameters were not always relevant for building relationships. In contrast to the perspective of the peers, some patients found a similar level of injury and the same gender much less important. Common interests, hobbies and age were more important for the patients. They wanted to exchange ideas with someone they shared similarities. The level of injury was of greater importance to patients with quadriplegia than to those with paraplegia. Counselling became more difficult for paraplegic peer counsellors the higher the level of injury in quadriplegic patients was. Patterson et al. [17] also reported that more focused support was necessary for peers and patients when lesion levels differed much between peers and patients.

The patients confirmed that the contact with the peer encouraged them, that they felt more motivated and that life became worth living again. Conversations about everyday situations helped to develop new perspectives. The honest and authentic manner of the peers supported the patients to envision how their lives can go on in spite of the wheelchair. Other studies regarding peer support during rehabilitation have also shown that peer support helps with the adjustments necessary for the new life after SCI [11] and also facilitates the learning process. [12, 19] Peer counselling during the initial rehabilitation phase can lead to better self-efficacy and therefore to improved health outcomes. Interestingly, a recent review of peer counselling in the outpatient setting showed quite similar findings. [20] Peer counselling facilitates empowerment of patients through a unique learning environment, responds to important unmet needs and represents an underappreciated potential. [20]

The peer counsellors' perspective offered new aspects. The importance of unplanned meetings with patients and the careful planning of the initial visit was shown. Furthermore, this study has shown that peers can feel burdened because of their close personal contact and emotional support. Clearly defined roles and task profiles for the peer counsellors within a rehabilitation clinic are therefore important. [21] Further support should be considered in order to better cope with these stressful situations. Training to deal with difficult situations or supervision for the peer counsellors would be beneficial.

\section{Limitations}

The present study consisted of six individual patient interviews and one focus group interview with peer counsellors.
The sample size did not allow to check, if saturation was reached, however, it gave important insights into the framework of peer counselling. The situation of peer counsellors should be investigated in further studies, and more interviews will be needed to generalize the results. Further, it may have been helpful to have several analysts studying the material with regard to the inter-observer reliability. [22]

\section{Conclusion}

It has been demonstrated that patients were encouraged and felt empowered by peer counselling. Unplanned meetings between patient and peers were essential and effective. Common interests, hobbies and the exchange of information on leisure activities helped in developing relationships. Framework conditions, such as initial visit timing, peer assignment, as well as various opportunities for exchange were important for a successful peer counselling program. Their positive attitude towards life and the authentic and honest nature of the peer counsellors were of great benefit to the patients. However, close contact with patients can sometimes lead to stressful situations for the peers. The need for support and training of peers should be examined in future studies.

Acknowledgements Many thanks to all peer counsellors and patients who made this study possible. We also like to thank Tim Shelton who is a native English speaker and working as peer counsellor for reviewing the translation of the quotes and the English language of the manuscript.

\section{Compliance with ethical standards}

Conflict of interest The authors declare that they have no conflict of interest.

\section{References}

1. Organization WH. Society ISC. Understanding spinal cord injury. In: Bickenbach J, editor.. International perspectives on spinal cord injury.. 1st edn. Malta: World Health Organization; 2013. p. 3-10.

2. Chamberlain JD, Deriaz O, Hund-Georgiadis M, Meier S, ScheelSailer A, Schubert M, et al. Epidemiology and contemporary risk profile of traumatic spinal cord injury in Switzerland. Inj Epidemiol. 2015;2:28.

3. Organization WH. Society ISC. Health Care and rehabilitation. In: Bickenbach J, editor.. International perspectives on spinal cord injury. 1st edn. Malta: World Health Organization; 2013. p. 67-91.

4. Wolfe D, Potter P, Sequeira K. Overcoming challenges: the role of rehabilitation in educating individuals with SCI to reduce secondary conditions. Topics in Spinal Cord Injury. Rehabilitation. 2004; 10:41-50.

5. May L, Day R, Warren S. Evaluation of patient education in spinal cord injury rehabilitation: knowledge, problem-solving and perceived importance. Disabil Rehabil. 2006;28:405-13. 
6. de Silva D. Evidence: helping people help themselves. London: The Health Foundation; 2011.

7. Houlihan BV, Brody M, Everhart-Skeels S, Pernigotti D, Burnett $\mathrm{S}$, Zazula J, et al. Randomized trial of a peer-led, telephone-based empowerment intervention for persons with chronic spinal cord injury improves health self-management. Arch Phys Med Rehabil. 2017;98:1067-76. e1.

8. Dennis C-L. Peer support within a health care context: a concept analysis. Int J Nurs Stud. 2003;40:321-32.

9. Lorig KR, Sobel DS, Ritter PL, Laurent D, Hobbs M. Effect of a self-management program on patients with chronic disease. Eff Clin Pract: Ecp. 2001;4:256-62.

10. Rohatinsky N, Goodridge D, Rogers MR, Nickel D, Linassi G. Shifting the balance: conceptualising empowerment in individuals with spinal cord injury. Health Soc Care Community. 2017;25:769-79.

11. Veith EM, Sherman JE, Pellino TA, Yasui NY. Qualitative analysis of the peer-mentoring relationship among individuals with spinal cord injury. Rehabil Psychol. 2006;51:289.

12. Ljungberg I, Kroll T, Libin A, Gordon S. Using peer mentoring for people with spinal cord injury to enhance self-efficacy beliefs and prevent medical complications. J Clin Nurs. 2011;20:351-8. (3-4)

13. Haas B, Price L, Freeman J. Qualitative evaluation of a community peer support service for people with spinal cord injury. Spinal Cord. 2013;51:295.

14. Balcazar FE, Kelly EH, Keys CB, Balfanz-Vertiz K. Using peer mentoring to support the rehabilitation of individuals with violently acquired spinal cord injuries. J Appl Rehabil Couns. 2011;42:3.

15. Tong A, Sainsbury P, Craig J. Consolidated criteria for reporting qualitative research (COREQ): a 32-item checklist for interviews and focus groups. Int J Qual Health care: J Int Soc Qual Health Care. 2007;19:349-57.

16. Mayring P. Qualitative content analysis: theoretical foundation, basic procedures and software solution. 2014. Klagenfurt. https:// nbn-resolving.org/urn:nbn:de:0168-ssoar-395173.

17. Patterson R, Bushnik T, Burdsall D, Wright J. Considerations of peer support for persons with high tetraplegia. Topics in spinal cord injury. Rehabilitation. 2004;10:30-7.

18. Forsythe E, Horsewell J. Sexual rehabilitation of women with a spinal cord injury. Spinal Cord. 2006;44:234.

19. Sherman J, DeVinney D, Sperling K. Social support and adjustment after spinal cord injury: influence of past peer-mentoring experiences and current live-in partner. Rehabil Psychol. 2004;49:140.

20. Divanoglou A, Georgiou M. Perceived effectiveness and mechanisms of community peer-based programmes for spinal cord injuries - a systematic review of qualitative findings. Spinal Cord. 2017;55:225.

21. Skeels S, Pernigotti D, Houlihan B, Belliveau T, Brody M, Zazula $\mathrm{J}$, et al. SCI peer health coach influence on self-management with peers: a qualitative analysis. Spinal Cord. 2017;55:1016.

22. Paul JL, Leslie H, Trainer AH, Gaff C. A theory-informed systematic review of clinicians' genetic testing practices. Eur J Hum Genet. 2018;26:1401-16. 